floor of the mouth are observed; the spatula being removed, the upper surface of the torgue is then viewed. The tongue is then firmly depressed, and the hard and soft palates, fauces, tonsils, pharynx, and in the vast majority of cases the epiglottis are observed.

1 New York Medical News, Nov. 2.

\section{AN ELECTRIC HOT-WATER BOTTLE.}

To those who practise in civilised regions where electric lighting is in operation, a suggestion, which we find in the Philadelohia Medical Journal, may prove useful - namely, that where the application of heat is desired this may be arranged by the simple plan of wrapping an ordinary electric light bulb, attached to a long flexible conducting cord, in a layer or two of cloth, and applying it to the part. The heat given off is moderate and continuous. For local pains in the chest or the abdomen, and for neuralgic pains in the head, such an arrangement has all the advantages of the hot-water bottle, in addition to which it has the great one of not going cold. It may also be used to "iron" the painful parts in cases of muscular rheumatism or in sciatica. It may be well to remember that the cloth in which the bulb is wrapped should be of woollen fabric or of silk, for the temperature attained by a lamp which is well wrapped up, approaches so nearly to that which will set fire to cotton fabrics that there might be danger if this precaution were neglected.

\section{THE ELECTROCUTION OF CZOLGOSZ}

From an account of the execution of Czolgosz contributed to the New York Medical Record by Dr. MacDonald, who was present, it appears that two electrical contacts were made occupying in all one minute and five seconds. In the first contact the electromotive pressure was maintained at 1,800 volts for seven seconds, then reduced to 300 volts for 23 seconds, increased to 1,800 volts for four seconds, and then reduced to 300 volts for 26 seconds, when it was broken. Why all this was done is not stated. It was conceded by all the witnesses, we are told, that conscious life was absolutely destroyed the instant the first contact was made. The poles had been connected with the head and leg, and the moment the circuit was completed by the turning of the switch the body was thrown into a state of extreme rigidity, every fibre of the muscular system appearing to be held in a marked condition of tonic spasm. At the same time consciousness, sensation and motion were apparently absolutely abolished. How under these circumstances the spectators arrived at any conclusion as to the state of consciousness of the victim we do not know. We have no doubt it was so. But it is quite clear that when all the muscles, the sole means by which expression can be given to any feeling, are in a state of tonic spasm, any such consciousness as a man might retain would have but little chance of giving evidence of its persistence.

\title{
Progress in NEUROLOGY.
}

Myasthenia Gravis.-Up to the present time no pathological changes have been found, either in the nervous system or muscles, which might account for the condition. Laquer and Weigert ${ }^{1}$ have, however, recently published an account of, clinically, a typical case of myasthenia gravis, in which definite changes were found on autopsy. In the situation of the thymus gland a tumour was found, which, microscopically, was found to consist of small cells, lymphoid cells, larger epithelioid cells, and Hassell's bodies. In the deltoid and diaphragmatic muscles, it was found that at many points both in the sheath of the muscles and between the muscle fibres, there was a great invasion of small lymphoid cells which closely resembled those found in the thymus tumour, and to a lesser extent the larger epithelioid cells were also present. The muscle fibres themselves, however, appeared to be normal. The combination of myasthenia with disease of the thymus is noteworthy, but it is hardly probable that such an association is at all common in view of detailed accounts of the pathological condition of previous cases.

Progressive Muscular Atrophy.-Williamson ${ }^{2}$ has recorded the pathological changes in a case of progressive muscular atrophy. Lateral sclerosis has so often been found post-mortem in such cases that some writers have grouped this affection and amyotrophic lateral sclerosis as one and the same disease. But Beevor, J. B. Charcot, and others have published cases in which the lateral pyramidal tracts were unaffected, and this one is yet another. The disease had lasted 20 years. There was slowly progressing muscular atrophy, with paralysis of the small muscles of the hands, the forearm, and upper arm muscles, and finally the muscles of the neck. Sensation was always unaffected, and the legs, bladder, and rectum were normal. Thus clinically there were no symptoms to indicate any affection of the lateral pyramidal tracts at the end of 20 years. Both by Marchi's and Weigert's methods the white matter of the spinal cord was found to be normal. In the middle and lower cervical region the anterior cornual cells had disappeared, and the fine delicate nerve fibres were greatly diminished in numbers, whereas the nerve fibres entering the posterior horns from the posterior roots were quite normal.

Tumours of the Frontal Lobe of the Brain.Höniger ${ }^{3}$ remarks that a diagnosis may be made when there is disturbance of the psychical functions. The mental alteration may express itself in the form of loquacity and a tendency to joking combined, and this condition of irrepressible quibbling, is especially marked when the left frontal lobe is the seat of the tumour. Another trait is an ataxic gait which resembles that of a drunken person, which is attributable to a weakness or paresis of the trunk muscles in the lumbo-sacral region, and sometimes to a spasmodic contraction of these muscles. A permanent paralysis of these muscles follows as the tumour grows and enlarges, involving the cortex of the superior frontal convolution. In proportion as the tumour approaches the third left frontal convolution, speech disturbances predominate. Other symptoms develop if the tumour approaches the motor area. If the tumour starts in the basal aspect of the lobe, its proximity to the olfactory and optic nerves may give rise to disturbances of those nerves. It will be remembered that Munk by experimental ablation of 